\title{
Accuracy of Image Analysis in Quantitative Study of Cement Paste
}

\author{
Shu-Xia FENG ${ }^{1, a}$ and Pei-Ming $\mathrm{WANG}^{2, \mathrm{~b}}$ \\ ${ }^{1}$ School of Architectural Engineering, Shandong Yingcai University, Jinan 250104, China \\ ${ }^{2}$ Key Laboratory of Advanced Civil Engineering Materials, Education of Ministry, School of Materials \\ Science and Engineering, Tongji University, Shanghai 201804, China

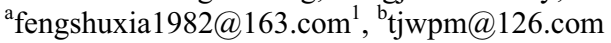

\begin{abstract}
Quantitative study on cement paste especially blended cement paste has been a hot and difficult issue over the years, and the technique of backscattered electron image analysis showed unique advantages in this field. This paper compared the test results of cement hydration degree, $\mathrm{Ca}(\mathrm{OH})_{2}$ content and pore size distribution in pure pastes by image analysis and other methods. Then the accuracy of qualitative study by image analysis was analyzed. The results showed that image analysis technique had displayed higher accuracy in quantifying cement hydration degree and $\mathrm{Ca}(\mathrm{OH})_{2}$ content than non-evaporable water test and thermal analysis respectively.
\end{abstract}

\section{Introduction}

In recent years, the application of backscattered electron image analysis (BSE-IA) technology in the research of cement paste in increasingly by researchers pay attention to[ 1,2$]$. In blended cement paste, it's hard to determine hydration progress quantitatively due to coupling reaction between cement and supplementary cementious materials. Compared to conventional research methods, BSE-IA technology has unique advantages in the quantitative study of blended cement paste. Unlike the secondary electron imaging, technique of backscattered electron imaging not been applied widely. There are two main reasons for its limited application, one is the difficulties of sample preparation and the other is the uncertainty of test accuracy. Some works have been done to determine appropriate preparation process for polished sample of cement paste by P.M.Wang et al. [3,4]. However, few works has been done to investigate the test accuracy of BSE-IA in quantitative study in cement paste. There is only one paper published in 1997 showing some research results about it [5]. In this paper, the accuracy of BSE-IA quantifying porosity and $\mathrm{CH}$ content in pure cement paste was analyzed by comparing the results of BSE-IA with that of other methods including methanol adsorption and thermal analysis. The results showed that there was good consistency between the porosity data determined by the methanol adsorption and BSE-IA separately. However, there was obvious difference in pore size statistic by the two methods,

*Corresponding author:fengshuxia1982@163.com 
pores larger than $36.8 \mathrm{~nm}$ were statistical calculated by the former while pores larger than $500 \mathrm{~nm}$ by the later. There was no direct comparison result since thermal analysis determined $\mathrm{CH}$ content by mass while BSE-IA determined by volume.

In this paper, the accuracy of BSE-IA quantifying cement hydration degree and $\mathrm{CH}$ content was analyzed by comparing the results determined by BSE-IA with the results determined by other methods including non-evaporable water (Wn) test and thermal analysis.

\section{Materials and Methods}

Portland cement P.I 52.5 was used for pure cement paste (PC) preparation in this project. The chemical compositions of cement were presented in table 1. PC paste was prepared at the water to cement ratio of 0.5 . The paste was cured in saturated lime water after the first $24 \mathrm{~h}$ hydration until test time at $20^{\circ} \mathrm{C}$.

At 1, 3, 7, 28,90,180 and 360 days, the hardened cement paste was sliced into several sections, and the hydration was stopped by water-ethanol replacement. After that, the sections were dried in vacuum desiccation at $40{ }^{\circ} \mathrm{C}$ for 24 hours and then stored in a desiccator oven to avoid further hydration and any possible carbonation/alteration.

TABLE 1 CHEMICAL COMPOSITIONS OF CEMENT [WT/\%]

\begin{tabular}{cccccccccc}
\hline $\mathrm{CaO}$ & $\mathrm{SiO}_{2}$ & $\mathrm{Al}_{2} \mathrm{O}_{3}$ & $\mathrm{Fe}_{2} \mathrm{O}_{3}$ & $\mathrm{MgO}$ & $\mathrm{SO}_{3}$ & $\mathrm{~K}_{2} \mathrm{O}$ & $\mathrm{TiO}_{2}$ & $\mathrm{MnO}$ & $\mathrm{SrO}$ \\
\hline 64.50 & 21.00 & 4.94 & 3.27 & 1.11 & 2.70 & 0.76 & 0.19 & 0.05 & 0.11 \\
\hline
\end{tabular}

Polished samples of paste were prepared for BSE-IA, the specific process of polished sample preparation was presented in detail in other paper of author [3]. Samples for mercury intrusion porosimetry test were made into spherical to investigate pore size distribution in cement pastes while samples for thermal analysis and selective chemical solution test were ground and sieved.

A scanning electron microscope (FEI QUANTA200FEG) was used to take pictures at backscattered electron mode. Then, cement hydration degree, $\mathrm{Ca}(\mathrm{OH})_{2}(\mathrm{CH})$ content, pore size distribution and slag hydration degree were determined quantitatively by BSE images analysis.

The amount of non-evaporable water was determined according to the procedure proposed in existing literature [6]. This value was used as a means to estimate the hydration degree of cement in $\mathrm{PC}$ paste. The amount of $\mathrm{CH}$ in pastes was determined quantitatively by thermogravimetric analysis (TG). $(1.00 \pm 0.01) \mathrm{g}$ powder specimen $(80 \mu \mathrm{m})$ was analyzed from RT to $1000^{\circ} \mathrm{C}$ at a heating rate of $10^{\circ} \mathrm{C} / \mathrm{min}$. Each temperature interval corresponds to certain decomposition of different phases in cement paste and the amount of $\mathrm{CH}$ could be assessed from the positions of decalescence peak between $500-570{ }^{\circ} \mathrm{C}$ [7].

\section{Results and Discussions}

Cement Hydration Degree Determination by BSE-IA and Wn Test. In this study, cement hydration degree in PC paste from 1 to 360 days was determined by BSE-IA. The image processing was carried out by an image processing software (Image-Pro Plus 6.0) based on the entropy maximization of the grey level histogram $(\mathrm{GLH})$ curve in order to extract the area fraction of unhydrated cement (UHC).As shown in Fig.1, images were processed according to the following steps: firstly, threshold by the entropy maximization of the GLH curves so that a binarised image corresponding to the anhydrous particles is obtained; secondly, close holes in anhydrous particles; finally, rebuild the phase of UHC and 
acquire the area fraction of UHC. The calculation formulas could be seen in an existing literature [8].

For comparison, cement hydration degree in PC were also determined by Wn test. As shown in Fig.2, the values from two methods showed good consistency, which proved the reliability of BSE-IA in cement hydration degree study.

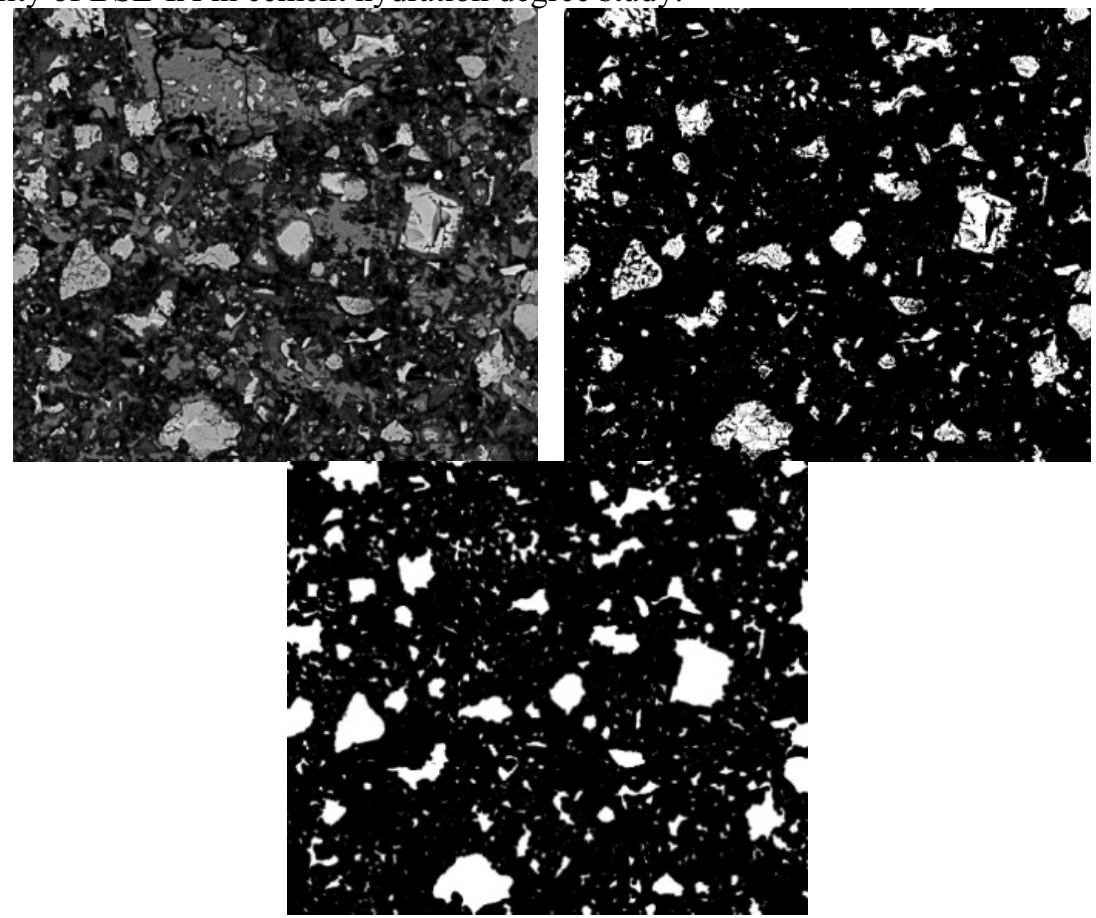

(a) Original BSE image

(b) Binary image

(c) Refinement image

Fig.1 Binary image processing for UHC

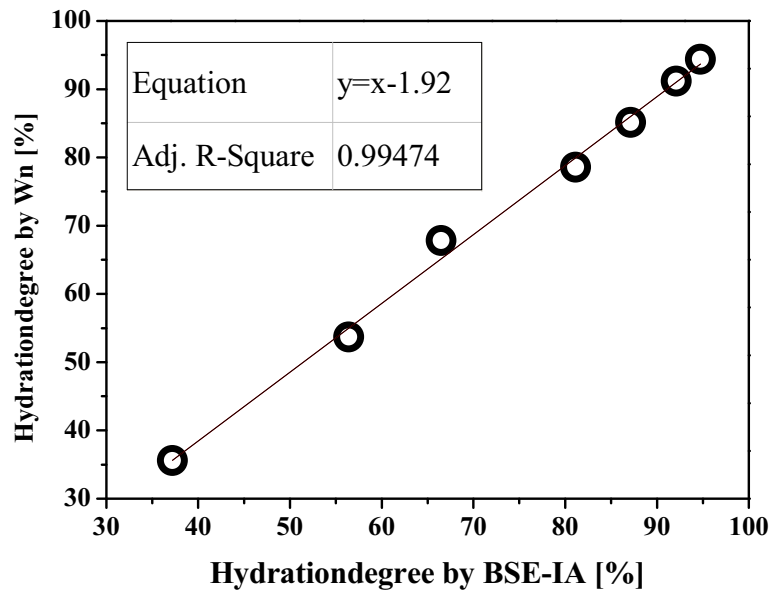

Fig.2 Hydration degree of cement clinker determined by BSE-IA and Wn test separately

CH Content Determination by BSE-IA and TG.CH content in PC paste was determined by BSE-IA and TG separately. As shown in Fig.3, BSE images for $\mathrm{CH}$ content determination were processed according to the following steps: firstly, threshold by the entropy 
maximization of the GLH curves to obtain binarised image of $\mathrm{CH}$; then, refine the original binary image to increase the accuracy of binarization.

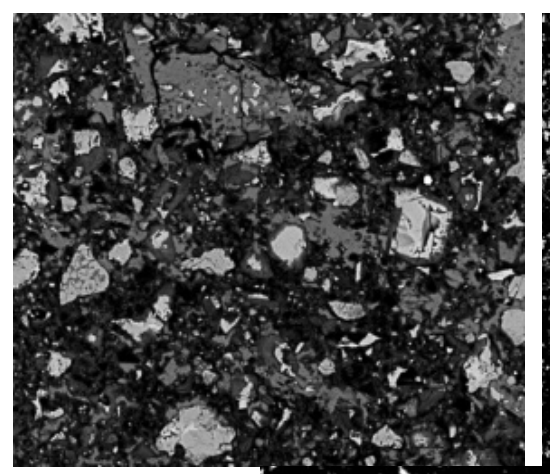

(a) Original BSE image

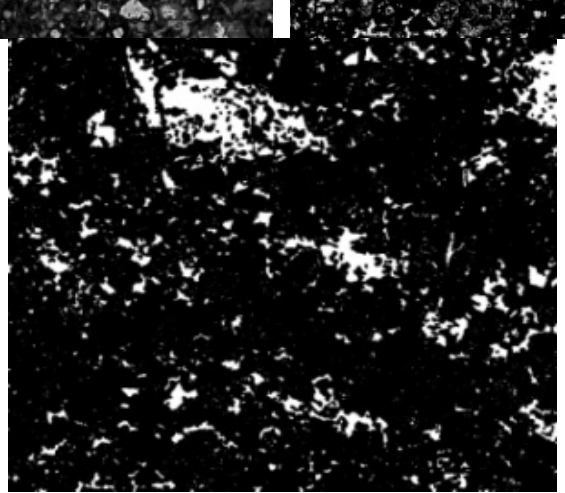

(b) Binary image

(c) Refinement image

Fig.3 Binary image processing for $\mathrm{CH}$

It should be noted that the $\mathrm{CH}$ content determined by BSE-IA was volume fraction while determined by image analysis was mass fraction. Therefore, $\mathrm{CH}$ content by volume by BSE-IA should be converted to content by mass so that results could be used to compare the consistency of the two methods. According to the conversion method presented in Eq.1 and relative parameter values shown in table 2, volume fraction of $\mathrm{CH}$ determined by BSE-IA was converted to mass fraction. Then, it was compared with the value determined by TG, as shown in Fig.4. It was obvious that the values from two methods showed good consistency, which proved the reliability of BSE-IA in $\mathrm{CH}$ content determination.

$$
C H_{m}=\frac{\rho_{C H}}{\rho_{\text {paste }}} \times C H_{v}
$$

Where, $\mathrm{CH}_{m}$-CH content by mass in PC paste; $\rho_{\mathrm{CH}}$-bulk density of $\mathrm{CH}$ formed in PC

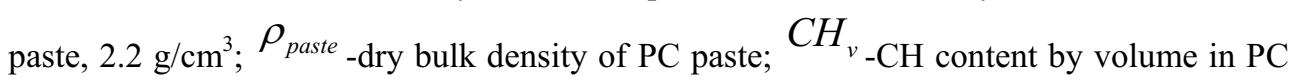
paste. 
TABLE $2 \rho_{\text {paste }}$ AND $\mathrm{CH}_{v}$ IN PC PASTE AT DIFFERENT AGE

\begin{tabular}{cccccccc}
\hline Age [d] & 1 & 3 & 7 & 28 & 90 & 180 & 360 \\
\hline$\rho_{\text {paste }}\left[\mathrm{g} / \mathrm{cm}^{3}\right]$ & 1.28 & 1.41 & 1.46 & 1.57 & 1.70 & 1.71 & 1.79 \\
$C H_{v}[\%)$ & 4.77 & 8.66 & 10.53 & 13.92 & 16.71 & 17.39 & 18.8 \\
\hline
\end{tabular}

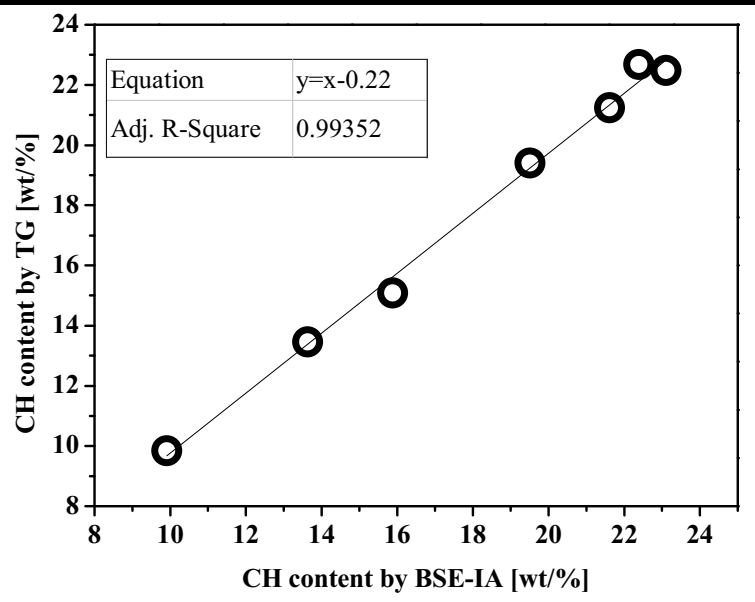

Fig.4 Results of CH mass fraction determined by BSE-IA and TG separately

\section{Conclusions}

BSE-IA can be used to determine volume content of several phases quantitatively in cement paste such as unhydrated cement and $\mathrm{CH}$. Then, the hydration process of cement paste could be characterized by those quantitative indexes. The test accuracy of BSE-IA technique in quantitative study of different phases has been estimated through comparing to other familiar methods. Furthermore, advantages and disadvantages of this technique were analyzed.

It is reliable and accurate of BSE-IA in cement hydration degree and $\mathrm{CH}$ content determination, which has been proved by the agreement of results determined by BSE-IA and $\mathrm{Wn}$ test, thermal analysis respectively.

\section{Acknowledgement}

The financial help of Natural Science Foundation of Shandong Province (Project No.ZR2014EMP011), Science and Technology Development Plan Project of Shandong Province (Project No. 2013YD06012), Housing Urban and Rural Construction in Shandong Province Science and Technology Plan (Project No. RK035) and A Project of Shandong Province Higher Educational Science and Technology Program (Project No. J14LA51) are gratefully acknowledged. 


\section{References}

1. M.B.Haha, K.D.Weekrt, B.Lothenbach, Quantification of the degree of reaction of fly ash, Cement and Concrete Research, 40 (2010) 1620-1629.

2. S.X.Feng, P.M.Wang, X.P.Liu, SEM-backscattered electron imaging and image processing for evaluation of cement volume fraction in both neat and slag blended Portland cement pastes, Journal of Wuhan University of Technology-Mater., 28 (2013) 968-972.

3. S.X.Feng, P.M.Wang, X.P.Liu, Preparation of flat-polished specimens of slag-blended cement paste for backscatteredelectron imaging, Advances in Cement Research, 24 (2012) 103-110.

4. P.M.Wang, S.X.Feng, X.P.Liu, Preparation of flat-polished specimens of cement paste for backscattered electron imaging and analysis (in Chinese), Journal of the Chinese ceramic society, 41 (2013) 211-217.

5. K.L.Scrivener, H.H.Patel, P.L.Pratt, et al., Analysis of phases in cement paste using backscattered electron images methanol adsorption and thermogravimetric analysis, In: Mater. Res. Soc. Symp. Proc., 86 (1985) 67-76.

6. K.O.Kjellsen, O. Knut, D.Detwiler, et al., Backscatt ered electron im aging of cement pastes hydrated at different temperatures, Cement and Concrete Research, 20 (1990) 308-311.

7. B.B. Sabir, S. Wild, J. Bai, Metakaolin and calcined clays as pozzolans for concrete: a review, Cement Concrete Composites, 23 (2001) 441-454.

8. P.M.Wang, S.X.Feng, X.P.Liu, Research approaches of cement hydration degree and their development(in Chinese), Journal of Building Materials, 8 (2005) 646-652. 